\title{
Evaluating National Emergency Indexes in Medical and Educational Centers
}

Ehsan Mohammadi1
Nemat-Allah Chaghazardi1
Mohsen Mohammadi1
Seyedeh Hoda Mousavi²
Ali Goli1
Shaaban Moradi1
Fakhri Shabazian1
${ }^{3}$ Ph.d Student Health Services Management, Student Research Committee, Kermanshah University of Medical Sciences,
Kermanshah, Iran. (Corresponding Author) Email:esfandnia2012@yahoo.com

Doi:10.5901/mjss.2015.v6n4s2p607

\section{Abstract}

In order to manage sections of emergency in an effective manner in various levels of headquarters and line, it is critical to have a tool to monitor and evaluate the performance. Thus, present research was developed aiming to evaluate national emergency indexes in medical and educational centers. The statistical society of ore sent research is all educational - medical centers of Kermanshah Medical University and we used census method. Indexes were gathered by means of forms completed in emergencies and analyzed by Spss 21 software and we used descriptive statistics including median and standard deviation. Findings indicate that the minimum rate of the percentage of patients settled during 6 hours is related to Imam Reza Hospital with 76.66 percent and also the minimum rate of the percentage of patients existing the emergency less than 12 hours was related to Mohammadi Kermanshahi Hospital equal to 85 percent. The minimum rate of unsuccessful CPR is related to Motazedi Hospital equal to zero percentage. The maximum rate of leaving with personal responsibility is related to Kermanshah's Imam Khomeini Hospital in rate of 18.94 percent. The minimum median of triage time duration in levels one, four and five are related to Motazedi Hospital and to Taleghani Hospital in levels two and three. Considering the fact that emergency is first level of patients' contact with the hospital, exact evaluation of emergency indexes, specially important indexes such as percentage of settled patients during 6 hours, percentage of patients leaving the emergency under 12 hours, and the triage time duration median are essential.

Keywords: Emergency, National indexes, Evaluation

\section{Introduction}

The emergency section is considered as the heart of a hospital and the proper and regular stream of affaires in this section could save many lives. No hospital could be considered as an ideal medical center if its emergency section lacks active and proper function and in case of such issue, other hospital services are affected by this huge problem (1). Usually, patient's first experience is related to emergency section and since they need treatment, immediate and special care, it is critical to understand patient's problem to satisfy them (2). Based on definition of Ministry of Health, treatment and medical education's standard and regulations evaluation office, the emergency centers are centers responsible for aiding and quick and general treatment of all emergency patients and accident injuries (3). Hospital emergency in one hand is responsible for receiving ill conditioned patients from pre hospital emergency or other medical centers and from the other hand they are responsible for stabilizing patients vital signs in order prepare them for entering the inpatient, special and surgical sections of the same or other hospitals, what's more this section faces a huge population of outpatients that have chosen emergency section for their treatment due to various reasons (4). Now a day's accidents and 
events result in more than 5 million deaths and more than 100 million enfeeblement annually (5). Reports indicate that accidents are responsible for $12 \%$ of global enfeeblements and not considering their result or meaning, they greatly effect on health systems that present required care and support for victims (6). Reasons of such injuries are also an extended collection of accidents including natural or human made disasters (7). Based on latest estimates of Universal health organization, 4100 traumas emerge in one million populations (8). It is also predicted that in year 2020, trauma will be the first or second main reason of death in developed and developing countries (9). Still, disaster management expertise believe that death resulted by disasters is only the peak of iceberg and the economic effect of these deaths could be especially ruinous for developing countries (10). This has led the global health organization to mention the increasing value of chronic diseases, non-contagion, trauma and depression in its health report of 2003 and asks for fast and continuous development of emergency centers. Road traffic injuries are also a general problem in the country. Iran has one of the highest rates of road accidents death and diseases in all over the globe (11). Also, disease pattern has changed in Iran during recent years (8). Emergency medical services are an important part of health care system which are noticed in most societies as a public product (12). There is no doubt emergency sections are among the most important, sensitive and dangerous sections of hospitals and its personnel including Doctors, Nurses, Office staff and service staff save several patients all over the country in daily basis, since if the disease isn't treated and analyzed properly in early moments of entering the hospital, maybe existence of specialized and very developed sections can't be very effective at saving the patient in fallowing hours and days (13). The emergency section is considered to be one of the most important parts of the hospital; because treating patients coming to this section in short time and highest quality is one of medical personnel duties. Emergency section should be organized I correct and proper manner since emergency section is very sensitive and service providing procedures in this section must be exactly noticed so we can present proper performance in emergency service providing and also to present fast and useful services by applying effective management, which all can be possible by proper managerial structure, effective procedures design and effective performance. Considering the critical and vital role of hospitals and also noticing the fact that organizing this section is far from satisfying condition in most of hospitals in our country since accompanying ad assistance is weak, expert employees (Doctors and Nurses) experience is limited and supportive services are not enough and in reach equipment's usually don't have proper quality, therefor emergency section is evaluated with other section and also before all of them and improving it to any possible level for the society will be a the first thing to do (14).

It is obvious that hospital and its various sections specially emergency, each face key and vital duties as an organization which should be evaluated with and before other unites and improving it as far as society is capable of should be the first thing to do. Medical emergency centers are among country's gnarl hospitals' critical and unavoidable sections in times of accidents considering its sensitive role in saving humans' lives (15). Almost 28\% of patients coming to the emergency center, are hospitalized in various sections of the hospital, therefor we should use it to maximum level by presenting proper services based on the budget spent for hospitalizing expenses (16). Emergency center as the entrance door of the hospital receives near 30 million patients annually. This section is the heart of health and medication system and improving its condition and organizing it is one of the most important priorities of ministry of health (17) and they expect to present timely and high quality services. What's more, this section is one of the most important parts of the hospital because patients coming to this section are in critical physical condition and considering their situation in shortest time and highest quality is the duty of medical and nursing staff in this section. Therefor presenting effective and timely services is possible in shadow of effective and functional function (14).

To ensure the efficiency of emergency services we should evaluate this section's performance. Nowadays there are various tools and methods to evaluate organizations' performance and if they are applied properly and continuously, they lead to improvement and responsibility of executive organizations and general trust to organizations' performance, efficiency and effectiveness in privet and public sectors (18). Hospital indexes are the most important signs of hospital performance in various areas. Therefore it is essential to pay general attention to all these signs since a hospital's performance is clearly obvious with a look at condition of hospital indexes and its weak and strengths points are revealed by deeper thinking about these indexes and it also shows indexes related to emergency section in various aspects. Finally 5 indexes were selected as prime indexes to evaluate in first stage and general ministry level and a summary of reasons to select these indexes are presented in fallow:

1- percentage of patients settled in less than 6 hours index

2- percentage of temporary settled in patients who have existed the emergency in less than 12 hours index

3- unsuccessful CPR percentage

4- leave percentage of emergency patients with their own responsibility

5- triage time duration median

Results of Azimy, 1999 indicated that among all executed CPRs the primarily success percentage was equal to 
$34 \%$ and $66 \%$ were unsuccessful and the final success was equal to $11 \%(19)$. results of Jaberi research indicated that all cases related to inside hospital heart restoration during 2009 indicated that in relation to 302 cases involving this procedure 72 cases (23.8\%) had the primarily success and 10 cases (3.3 percentage) had the final success, therefor the most important of increasing the efficiency of inside hospital heart restoration was the enthusiasm of the restoration team inside the hospital and quickest use of restoration team (20). results of Yarmohammadian 2012 shows that amount of releasing with personal satisfaction before intervention was 4.6, this rate was decreased to 2.8 percent 4 months after executing proper interventions such as creating proper communication between Doctor and patient, correct informing procedures while receiving a patient and presenting educational classes by hospital's clinical authority team (21). results of Kabirzade's research 2009 indicated that 108 individuals (2.2 percent) were dismissed by their own personal satisfaction and children's age median was 2 years old and their staying in hospital duration was 2 days. generally 95 individuals (88.7 percent) had insurance, 65 individuals (2.60 percent) lived in city, 22individuals (6.20 percent) were negative from psychiatric history and addiction in parents point of view, 100 (3.29 percent) individuals were hospitalized due to sickness and non-surgical reasons while others were surgical. the person signing the letter of satisfaction was usually father of the patients, 78 individuals (3.72 percent), 108 patients were also released by their personal satisfaction that 20 (12 percent) were hospitalized again. the relation between release date and personal satisfaction was significant $(P=0.03)$. rate of release in Bu-Ali Hospital of Sarry and in comparison with other studies was in a similar domain and there weren't too many differences in reasons. but lacking the proper form which includes Doctors' explanation to parents about the grand and severe consequences of release with personal satisfaction and also presents the real reason of such releases which is noticeable in mentioned research (22). findings of Vahdat's research (2009) shows that in various sections of hospital, the under surveillance section with 59.3 percent and emergency section with 23.3 percent had the highest amount of personal satisfaction and considering obtained results we could claim that improving medical services level and treatment equipment's could create a pleasant environment for patients and finally increases patients' satisfaction and therefor decrease the rate of release with personal satisfaction (23). Dehnady's research results in 2007 showed that among total number of 30764 patients coming to the hospital 25525 were outpatients, 5214 were inpatients and 25 individuals died. Median of inpatients, morning and night working shift and outpatients in morning, evening and night had a significant difference. Maximum of 2104 patients were hospitalized in night work shift, maximum 12443 outpatients were received in morning work shift and median of triage patients in night and morning and evening working shift in two levels of emergency and urgency has a meaningful difference. Finally considering the fact that maximum number of inpatients were in night shifts, more attention to this work shift could have a critical role in saving patients life from various aspects (24). Generally, the aim of presenting indexes of emergency section was to achieve integrated function index for emergency sections and also clarifying strengths and weak points and also planning to achieve these sections' goals in specific directions, so present research was designed and executed to study national emergency indexes in medical-educational center of Kermanshah Medical University during 2011-2012.

\section{Research Method}

Sample society of present research was all medical-educational centers of Kermanshah City Medical University and we used census method, emergency indexes' data during 2014 were gathered by means of completed forms gathered from hospitals' emergency centers and were analyzed by Spss 21 software, we used descriptive statistic indexes including median and standard deviation for analysis. 


\section{Results}

\begin{tabular}{|c|c|c|c|c|c|c|c|c|c|}
\hline \multirow[b]{2}{*}{ Hospitals' name } & \multirow[b]{2}{*}{ 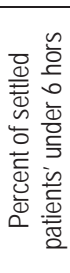 } & \multirow[b]{2}{*}{ 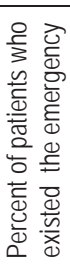 } & \multirow[b]{2}{*}{ 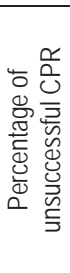 } & \multirow[b]{2}{*}{ 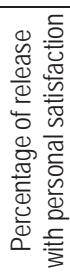 } & \multicolumn{5}{|c|}{ Median of triage duration for each level } \\
\hline & & & & & $\frac{\overrightarrow{1}}{\stackrel{\Phi}{\Delta}}$ & $\frac{\sim}{\stackrel{D}{\Delta}}$ & $\frac{m}{\stackrel{m}{\Xi}}$ & $\frac{\Delta}{\stackrel{\Delta}{\Delta}}$ & 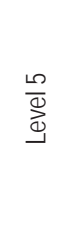 \\
\hline Imam Reza Hospital & 79.66 & 91 & 69.28 & 12.48 & 1 & 1.86 & 4.5 & 6.68 & 9.218 \\
\hline Imam Khomeine Hospital & 98.96 & 99.54 & 67.80 & 18.94 & .8 & 1.86 & 4 & 5.2 & 5.8 \\
\hline Taleghani Hospital & 95.73 & 93 & 30.73 & 9.12 & .2 & .7 & 1.1 & 3 & 4 \\
\hline Imam Ali Hospital & 95 & 95 & 45 & 9 & .4 & .8 & 3.4 & 7.2 & 11.2 \\
\hline Farabi Hospital & 99.98 & 91 & 73.90 & 13.62 & 1.3 & 4.2 & 5.7 & 6.65 & 7.75 \\
\hline Motazedi Hospital & 100 & 100 & 0 & 1 & 0 & 1.46 & 2.1 & 2.06 & 2.35 \\
\hline Mohammad Kermanshahi Hospital & 92 & 85 & 58 & 2 & .9 & 1.55 & 4.3 & 9.4 & 17 \\
\hline Imam Khomeini Islam Gharb & 99.98 & 100 & 56 & 3 & .4 & .8 & 3.4 & 7.2 & 11.2 \\
\hline Sarpol Zahab Merytam's Hospital & 95 & 95 & 78 & 11 & .83 & .95 & 1.8 & 9.63 & 13.83 \\
\hline Hazrat Abolfazl Ghasre Shirin & 99.96 & 100 & 62 & 1 & 1.4 & 4.35 & 5.5 & 6.58 & 7.05 \\
\hline Alzahra Guilan Gharb & 100 & 100 & 69 & 1 & .6 & 1.5 & 2.3 & 6.1 & 7.8 \\
\hline Imam Khomeine Sanghar & 89 & 95 & 67 & 4 & .7 & 2.53 & 11 & 19.2 & 24.38 \\
\hline Dr. Chamrean Kangavar & 100 & 99 & 48 & 1 & .05 & 1.7 & 5.3 & 9.1 & 10.8 \\
\hline Moaven Hospital Sahne & 100 & 100 & 70 & 2 & 1.05 & 1.9 & 4.3 & 16.3 & 27.3 \\
\hline Harsin Merytam & 98 & 99 & 77 & 4 & .43 & .75 & 2.8 & 5.8 & 8.075 \\
\hline Ghods Paveh & 95 & 97 & 73 & 1 & .73 & 7.35 & 18 & 23.5 & 27.25 \\
\hline Hazrat Rasoul Hospital Javanroud & 99 & 100 & 57 & 1 & 1 & 2.1 & 2.4 & 7.5 & 7.75 \\
\hline Total & 97 & 97.27 & 58 & 4.58 & .66 & 2.19 & 4.8 & 8.56 & 11.1 \\
\hline
\end{tabular}

Based on above table, the minumm amont of settled patients in less than 6 hours is related to Imam Reza hospital with 76.66 percent and also the minimum percentage of patients released from emergency ubder 12 hours is related to Mihammad Kermanshahi hospital with rate of 85 percent. The lowest rate of unsuccessful CPR is related to Motazedi Hospital with 0 percent. The highest rate of leaving with personal satisfaction is related to Kermanshah Imam Khomeini Hospital with 18.94 percent. The minimum triage time duration in level one is related to Motazedi Hospital, in second level Taleghani Hospital, in third level taleghani Hospital, in forth level Motazedi Hospital and in fifth level is related to Motazedi Hospital.

Table (2). Median and standard deviation related to each of indexes

\begin{tabular}{|c|c|c|c|c|c|c|c|c|c|}
\hline & \multirow{2}{*}{ 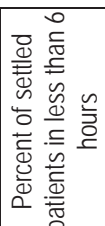 } & \multirow[b]{2}{*}{ 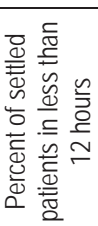 } & \multirow[b]{2}{*}{ 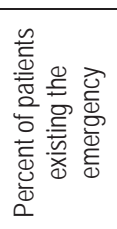 } & \multirow[b]{2}{*}{ 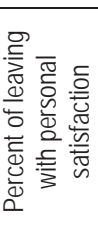 } & \multicolumn{5}{|c|}{ Triage time duration for each level of Triage } \\
\hline & & & & & $\frac{-1}{\stackrel{D}{d}}$ & $\frac{\sim}{\stackrel{\Xi}{\Phi}}$ & $\frac{m}{\stackrel{\Phi}{\Phi}}$ & $\frac{⿱ 亠 凶}{\mathrm{~d}}$ & $\frac{n}{\stackrel{d}{\omega}}$ \\
\hline median & 96.3100 & 96.4435 & 58.9241 & 5.5976 & .6935 & 2.1388 & 4.8176 & 8.8882 & 11.9266 \\
\hline Standard deviation & 5.39999 & 4.38169 & 19.67108 & 5.63183 & .40659 & 1.71513 & 4.07250 & 5.64955 & 7.69687 \\
\hline minimum & 79.66 & 85.00 & .00 & 1.00 & .00 & .70 & 1.10 & 2.06 & 2.35 \\
\hline maximum & 100.00 & 100.00 & 78.00 & 18.94 & 1.40 & 7.35 & 18.00 & 23.50 & 27.30 \\
\hline
\end{tabular}

The maximum median is related to percent of settled patients in less than 6 hours with standard deviation of 5.39999 and the minimum amount is related to Triage time duration median in level one Triage equal to .6935 and standard median of .40659 . 


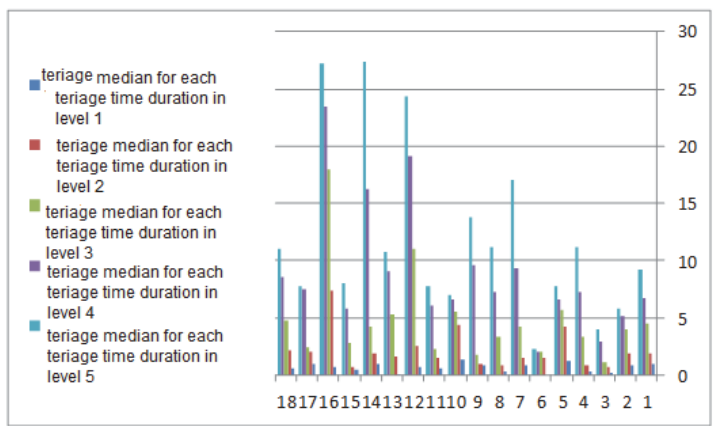

Diagram (1). Triage time duration in each five levels of Triage

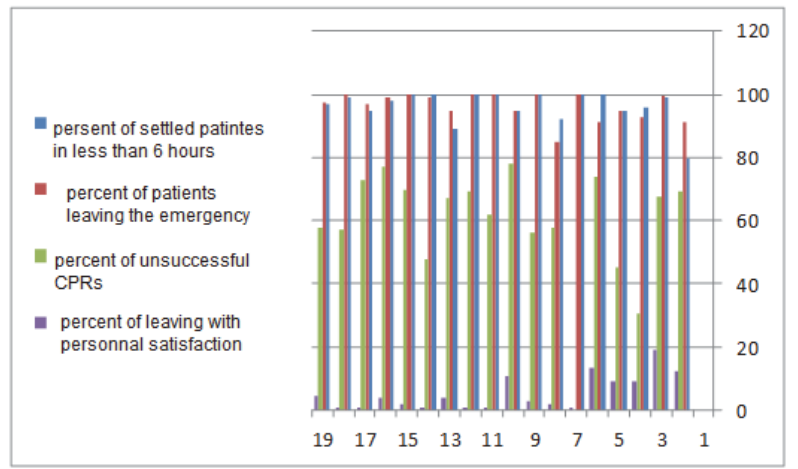

Diagram (2). Emergency national indexes condition

\section{Discussion and Conclusion}

Considering findings of present research, noticing emergency national indexes announced by ministry of health to medical centers is an important and vital issue since the emergency section is the beating heart of a hospital and the first level of emergency patients contact with medical and healthcare services. Therefor principal analyzing and evaluating such announced indexes by Ministry of Health and medical care to improve hospitals' emergency service quality seems critical. The minimum rate of settled patients in less than 6 hours is related to Imam Reza Hospital y 79.66 percent. Also the minimum rate of patients existing the hospital from the emergency section in less than 12 hours is related to Mohammad Kermanshahi Hospital by rate of 85 percent. The minimum rate of unsuccessful CPR is related to Motazedi Hospital which is zero percent. This is similar to results obtained by Azimi's research in 1998. The highest rate of leaving with personal satisfaction is related to Kermanshah Imam Khomeini Hospital which is 18.94. Results of Yarmohammadian research (2012) and Kabirzadeh (2009) and Vahdat's research (2010) are all in accordance with our research. The minimum median of triage in level one and level five is also related to Motazedi Hospital and is in accordance with Dehnahadi Moghadam research results (2007).

\section{Acknowledgements}

This Research Project has been financially supported by Student Research Committee, Kermanshah University of Medical Sciences (Grant No.93282). 


\section{Refrences}

H.R. Structure, process and activities of emergency sections in Tehran Medical University's Hospitals, hygienic, health faculty and research institute Journal, 13-22(4)4:2006.

M V, P D. An organizational wide approach to improving ED patient satisfaction one community feeding hospital. Journal of Emergency Nursing. 1999;25: 192-8.

Health web, instruction, standard and evaluating principals of public hospitals of the country, 1993, medical, appendix number 75234. In: education, editor. Tehran: Ministry of Health and medical Care, 1993.

Sulluzzo R, A T , al Me. Emergency department management -principles and applications. In: USA, editor. USA: MOSBY; 1997.

Organization WH. Health systems: Emergency-care systems. Sixteen world health assembly. Reported by the secretariat, 2007.

M K, NS Z, M R, al e .Injury epidemiology in Kermanshah: the National Trauma Project in Islamic Republic of Iran. La Revue de Santé de la Méditerranée Orientale. 2009;15(1):64-57.

Disaster Drathco. Disaster reduction and the human cost of disaster iran2007 [cited 200720 August 2007]. Available from: www. irinnews.org/IndepthMain.aspx? Indepthld=14\&Reportld=62446.

Organization PAH. Disasters: Preparedness and mitigation in the Americas. USA: News and Information for the International Community, 2004.

B R, M S, M G. Childhood trauma fatality and resource allocation in injury control programs in a developing country. BMC Public Health. 2006;6:122-17.

UN. Reducing disaster risk: A challenge for development. WASHINGTON DC: The report, prepared by a UNDP-led team of internationally recognized specialists, 2004.

D kZ. Toward safety promotion among road users: Epidemiology and prevention of road traffic injuries in Iran. Published by Karolinska institute, department of public health sciences, division of social medicine, Stockholm: Sweden. 2009.

Bahrami Ma, Abadi Mare, Malki, A. Evaluating Performance of Pre hospital Services in Yazd during 2009 and first three months of 2010, research and scientific Journal of Yazd's Medical Faculty. 45-60: (30)4; 2010.

KA F, SP M, GT B. An experimental architecture for observation of triage related decision making. Conf Proc IEEE Eng Med Biol Soc2007; United States: Piscataway, NJ :IEEE Service Center,; 2007. p. 1774-7.

Rahmani, H, Arab Dam, Akbari Defa, Zarei Dh, structure, processes and activities of emergency sections in Educational Hospitals of Tehran Medical University, health faculty and research institute Journal. 22-13; (44), 2006.

Bohlul. R, Aleh A, Ale zen, Abolghasem. P, evaluating the structure, processes and activities of emergency sections in Educational Hospitals of Uremia and Tabriz Medical University, Iran's Medical University and Medical Health care Management and Medical Information Journal,, 1-37: 13, 12; 2001.

J H, S T. Patient need in the emergency department. Journal of Nursing Administration. 1999;29(50-43.(

Razavi Desha, Hospital's Emergency Section Indexes, In: Country, editor. Tehran: Ministry of Health and Medical Education, 2011.

Zadeh yad, evaluating performance and importance of its existence in Aras free restrict organization.

Azimi, B.; Motaghi, M.; Studying the Rate of Success of Heart Restoration in Educational-Medical Center of Besat Hammedan in First 6 Mounts of 2007, Help and Rescue Scientific Journal, 27-35: (6)2; 2007.

Yahya, J.; Lida, Ch.; Saieedeh, Mz.; Studying the Rate of Heart Restoration Success Inside the Hospital and Factors Related to That, Zanjan Medical University, 48-57: (75)19; 2011.

Yar Mohammadian, Mh.; Mojahed' F.; Vahidi, R., Raghipor, K.; Clinical Audit of Release with Personal Satisfaction in Eromieh Dr. Salavati Hospital. Health Information Management, 06-114:(7)9; 2012.

Kabiradeh, A.; Zadeh, R.; Saravi, Bam.; redundancy and reasons of release of Children with Personal satisfaction in Sari Bou-Ali Hospital during 2008. Northern Khorasan Medical University Journal. 57-62: (4)2; 2010.

Shaghaiegh, V.; Somaieh, H.; Fardin, M.; Effective Factors on Realizing Patients with Personal Satisfaction In Medical Center of Ghazvin Shahid Rajaiee, Guilan's Nursing and Tocology faculty Journal. 47-52: (64)20; 2010.

Anush, Dadam; yousef Dizech, Hoseiin, Deh.; Shabani, S.; comparison of number of Triage Patients in three work Shifts of Pursina Hospital of Rasht City, Guilan's Medical University Journal. 68-76: (65)16; 2004. 